\title{
Epidemiological and clinical characteristics of respiratory viruses in 4403 pediatric patients from multiple hospitals in Guangdong, China
}

Yajie Zhang ${ }^{1 \dagger}$, Lin Qiao ${ }^{2 \dagger}$, Jinxiu Yao ${ }^{3}$, Nan Yu ${ }^{4}$, Xiaoping $\mathrm{Mu}^{5}$, Shengqi Huang ${ }^{6}$, Bo Hu${ }^{7}$, Weixuan $\mathrm{Li}^{8}$, Feng Qiu', Fangyin Zeng ${ }^{10}$, Cong Chen ${ }^{11}$, Yuqiu Zhou ${ }^{12}$, Bashan Zhang ${ }^{13}$, Tian Cai ${ }^{14}$, Weijia Wang ${ }^{15}$, Xianjin $\mathrm{Wu}^{16}$, Yiwen Zhou ${ }^{17}$, Guochang Wang ${ }^{18}$, Bo Situ', Shuling Lan ${ }^{1}, \mathrm{Na} \mathrm{Li}^{1}$, Xiu Li ${ }^{1}$, Zihua $\mathrm{Li}^{1}$, Xin $\mathrm{Li}^{1}$, Congrong Wang ${ }^{1}$, Chao Yang ${ }^{1}$, Pingfeng Feng ${ }^{1}$, Hongxia Wang ${ }^{1}$, Sijing Zhu ${ }^{19}$, Yufeng Xiong ${ }^{1}$, Min Luo', Wenjuan Shen ${ }^{20}$, Xiumei $\mathrm{Hu}^{1 *}$ and Lei Zheng ${ }^{1 *}$

\section{Abstract}

Background: Acute respiratory infections (ARI) cause considerable morbidity and mortality worldwide, especially in children. Unfortunately, there are limited multi-center data on common viral respiratory infections in south China.

Methods: A total of 4403 nasal swabs were collected from children in 10 cities in Guangdong, China in 2019. Seven respiratory viruses, influenza A virus (IFA), influenza B virus (IFB), respiratory syncytial virus (RSV), adenoviruses (ADV) and parainfluenza virus types 1-3 (PIV1, PIV2 and PIV3), were detected by direct immunofluorescence antibody assay. The personal information and clinical characteristics were recorded and analyzed.

Results: The results showed that at least one virus was detected in $1099(24.96 \%)$ samples. The detection rates of RSV, IFA, ADV, PIV3, PIV1 and PIV2 were $7.13 \%$ (314/4403), $5.31 \%$ (234/4403), $4.02 \%$ (177/4403), $3.04 \%$ (134/4403), $1.70 \%(75 / 4403)$ and $1.16 \%(51 / 4403)$, respectively. The detection rate of RSV was highest in 0-6-month-old children at $18.18 \%(106 / 583)$, while the detection rate of IFA was highest in 12-18-year-old children at $20.48 \%$ (17) 83). The total detection rates in winter and spring were $35.67 \%$ (219/614) and $34.56 \%$ (403/1166), higher than those in summer, $17.41 \%$ (284/1631), and autumn, $19.46 \%$ (193/992).

Conclusions: RSV and IFA were the main respiratory viruses in children. With increasing age the detection rate of RSV decreased in children, but the trends for the detection rates of IFA and IFB were the opposite. This study provided the viral etiology and epidemiology of pediatric patients with ARI in Guangdong, China.

Keywords: Acute respiratory infections, Prevalence, Seasonal, Respiratory viral infections, Multi-center, China

\footnotetext{
*Correspondence: hxxm19860108@163.com; nfyyzhenglei@smu.edu.cn

${ }^{\dagger}$ Yajie Zhang and Lin Qiao contributed equally to this work

'Department of Laboratory Medicine, Nanfang Hospital, Southern Medical University, Guangzhou, China

Full list of author information is available at the end of the article
}

(c) The Author(s). 2021 Open Access This article is licensed under a Creative Commons Attribution 4.0 International License, which permits use, sharing, adaptation, distribution and reproduction in any medium or format, as long as you give appropriate credit to the original author(s) and the source, provide a link to the Creative Commons licence, and indicate if changes were made. The images or other third party material in this article are included in the article's Creative Commons. licence, unless indicated otherwise in a credit line to the material. If material is not included in the article's Creative Commons licence and your intended use is not permitted by statutory regulation or exceeds the permitted use, you will need to obtain permission directly from the copyright holder. To view a copy of this licence, visit http://creativecommons.org/licenses/by/4.0/ The Creative Commons Public Domain Dedication waiver (http://creativecommons.org/publicdomain/zero/1.0/) applies to the data made available in this article, unless otherwise stated in a credit line to the data. 


\section{Background}

Acute respiratory infections (ARI) including the common cold, otitis media, acute bronchiolitis, pharyngitis, and pneumonia are one of the main causes of morbidity and mortality worldwide, especially in children [1]. Common pathogens causing ARI include viruses, bacteria and fungi. Respiratory syncytial virus (RSV), parainfluenza viruses (PIV), influenza A virus (IFA), influenza B virus (IFB) and adenoviruses (ADV) are the main respiratory viruses found in children [2]. Stringent diagnostic criteria are used to confirm the diagnosis of ARI, but empiric treatment for ARI is still common. Given that the symptoms of respiratory infections are usually clinically similar, it is difficult to distinguish viral infections from bacterial infections based on symptoms [3]. Therefore, the accurate and timely detection of respiratory tract pathogens in the laboratory is of great significance for correct diagnosis.

The prevalence of each respiratory pathogen varies from region to region, possibly owing to differences in climate, culture, and geography. A better understanding of the epidemiological and clinical characteristics of respiratory infections leading to ARI is critical for the successful implementation of prevention, control, and treatment strategies. Although some studies on the epidemiology of respiratory infections including ARI have recently been reported for local areas of China [4, 5], there have been few articles reporting the epidemiological and clinical characteristics of respiratory viruses from multiple hospitals. To better understand the nature of respiratory infections in children, we analyzed epidemiological and clinical characteristics of respiratory infections in pediatric patients aged $0-18$ years from 16 hospitals in Guangdong, China in 2019.

\section{Methods}

\section{Study population and design}

We conducted a retrospective, observational study that included emergency, outpatient and inpatient pediatric patients from 16 hospitals in Guangdong, China. All pediatric patients with ARI admitted to from January 1 to December 31, 2019 were screened for eligibility. Inclusion criteria were age $<18$ years, admission to any of the hospitals for $<24 \mathrm{~h}$, and agreement to provide written informed consent. The participating hospitals were located in 10 cities of Guangdong province (Additional file 1). Pediatric patients with symptoms and signs of respiratory tract infection, such as fever, cough, expectoration, sore throat, nasal congestion, nasal discharge, shortness of breath, abnormal breath sounds on auscultation, chest pain and lower respiratory signs, and inflammatory injury in the lungs observed upon imaging analysis, were defined as having ARI.
The following data were obtained from enrolled participants: age, gender, time of year, clinical symptoms and laboratory information. The clinical characteristics and laboratory information were collected and analyzed.

\section{Sample collection and laboratory processing}

All admitted pediatric patients with symptoms of respiratory tract infection attending 16 hospitals had nasal swabs or a bronchial aspirate taken for the study of respiratory viruses. Respiratory viruses were identified by direct immunofluorescence antibody assay using the D3 Ultra DFA virus identification reagent (Diagnostic Hybrids, Inc., USA), including IFA, IFB, ADV, RSV, PIV1, PIV2, and PIV3. The assay was conducted according to the manufacturer's instructions. All the medical staff and laboratory staff of the participating hospitals had received standardized training. Their patients provided clinical information for research purposes by completing a standard questionnaire under the guidance of the trained clinician. All methods were performed in accordance with the relevant guidelines and regulations.

\section{Statistical methods}

Statistical analyses were performed using IBM SPSS statistical software version 20 for Windows (IBM Corp., Armonk, New York, USA). Descriptive frequencies were presented as mean \pm standard deviation and proportions. Chi-square tests and Fisher's exact tests were used for comparisons between groups in terms of categorical variables wherever appropriate. Multivariate logistic regression analysis was performed to identify factors associated with the outcomes of interest. A $P$-value < 0.05 was considered statistically significant.

\section{Results}

\section{Demographic Characteristics and Overall Prevalence of} Respiratory Viruses

A total of 4403 nasal swab specimens from pediatric patients with ARI in Guangdong, China in 2019 were analyzed (Fig. 1). Overall, $2520(57.23 \%)$ of the pediatric patients were male and $1883(42.77 \%)$ were female $(P<$ 0.05 ). The mean age was 4 years (range 0 months to 18 years), and the median age was 6 years.

The total virus detection rate of all cases was $24.96 \%$ (1099/4403); 1076 (24.44\%) of the specimens showed single infections and $23(0.52 \%)$ of the specimens showed multiple infections. Among the respiratory viruses, the detection rate of RSV was $7.13 \%$ (314/4403), which was the highest, followed by IFA $5.31 \%$ (234/ 4403), ADV $4.02 \%$ (177/4403), PIV3 3.04\% (134/4403), PIV1 $1.70 \%$ (75/4403) and PIV2 1.16 \% (51/4403) (Fig. 2). The total virus detection rate in males was $25.40 \%$ (640/ $2520)$, and it was $24.38 \%(459 / 1883)$ in females $(P>$ $0.05)$. 

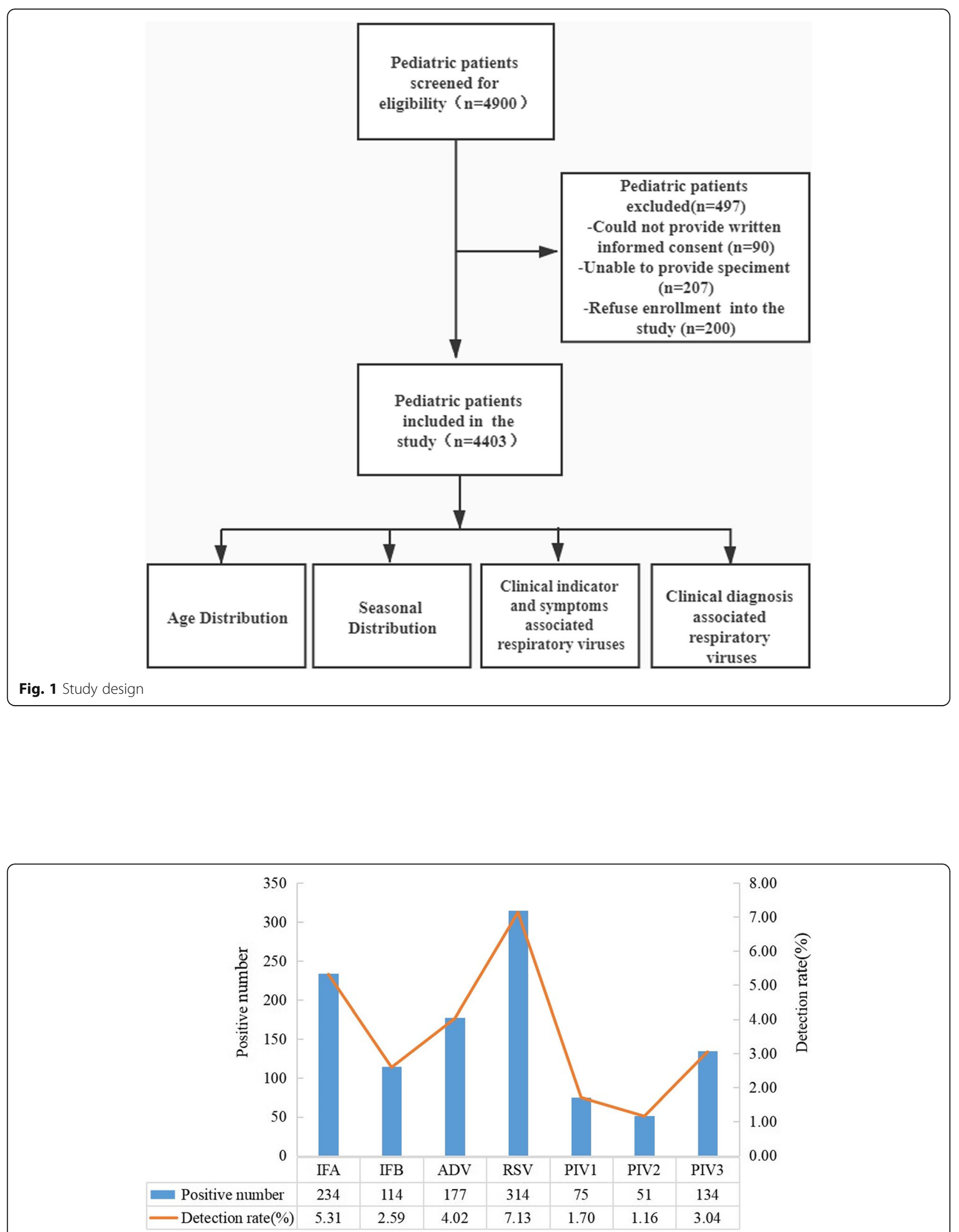

Fig. 2 The detection rate of respiratory viruses in pediatric patients with ARI in Guangdong, China, 2019 


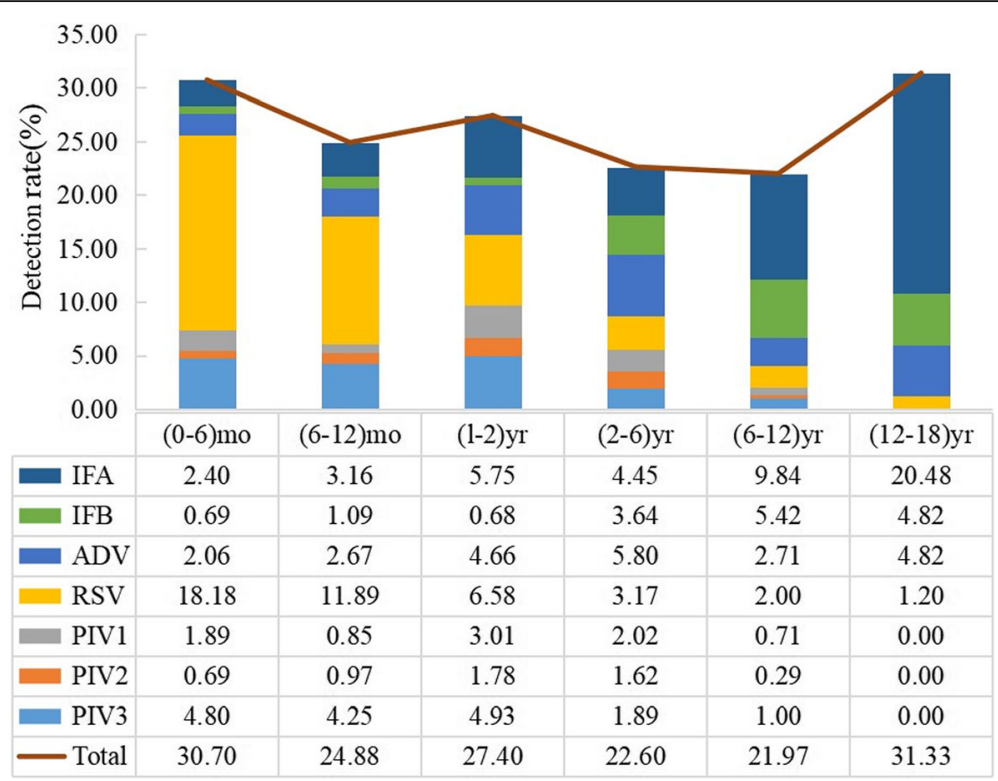

Fig. 3 Age distribution of respiratory viruses in pediatric patients with ARI in Guangdong, China, 2019. Note: There was statistically significant associations between respiratory virus (IFA, IFB, ADV, RSV, PIV1, PIV2 and PIV3) and age group $(P<0.05$, for all comparisons).

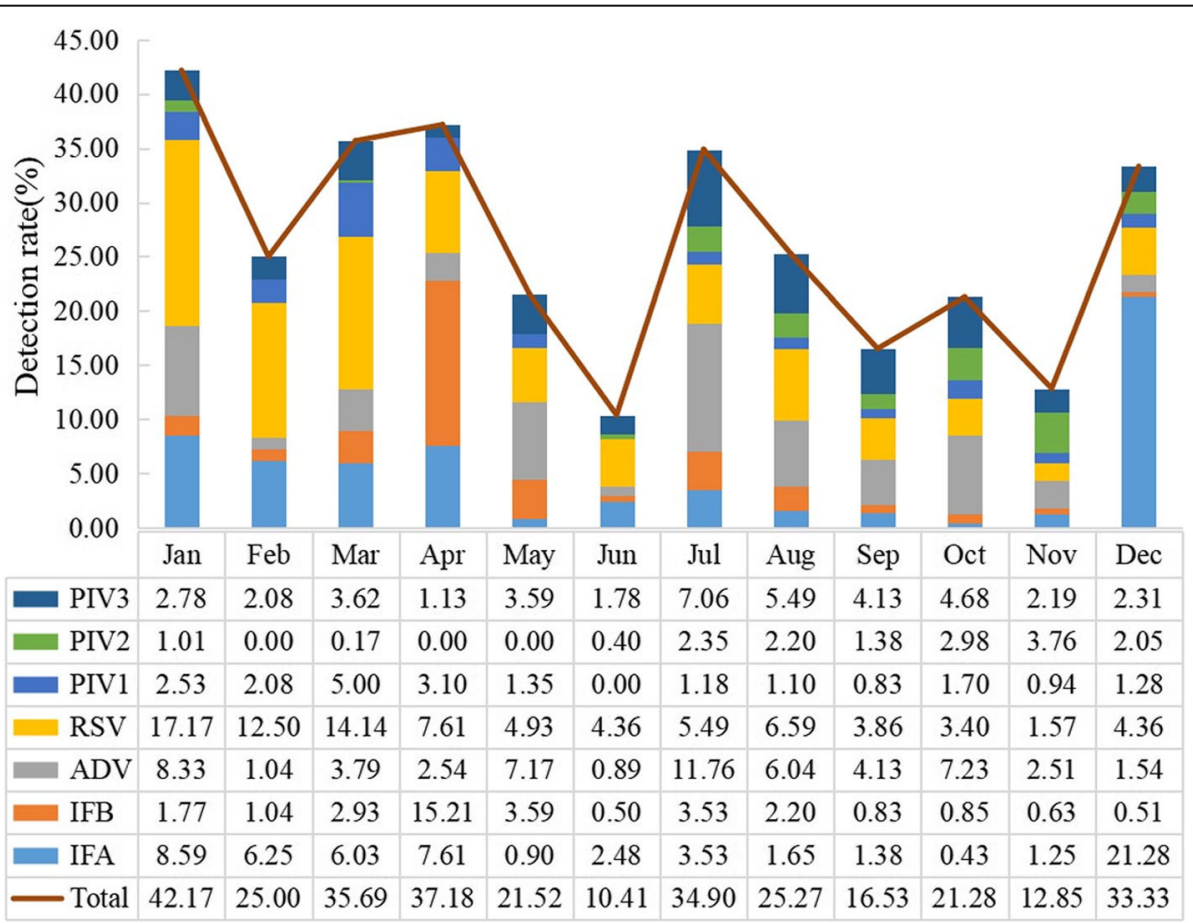

Fig. 4 Seasonal distribution of respiratory viruses in pediatric patients with ARI, 2019. Note: There were statistically significant associations between respiratory virus (IFA, IFB, ADV, RSV, PIV1, PIV2 and PIV3) and month ( $P<0.05$, for all comparisons). 


\section{Age-related Prevalence of Respiratory Viruses}

The distribution of respiratory viruses among different age groups is shown in Fig. 3. The virus detection rates in the 0-6-month-old group, 6-12-year-old group, 1-2year-old group, 2-6-year-old group, 6-12-year-old group and 12-18-year-old group were $30.70 \%$ (179/ 583), $24.88 \%$ (205/824), $27.40 \%$ (200/730), $22.60 \%$ (335/1482), $21.97 \%(154 / 701)$ and $31.33 \%(26 / 83)$, respectively. In the 0-6-month-old group, the top two detected viruses were RSV $(18.18 \%, 106 / 583)$ and PIV3 $(4.80 \%, 28 / 583)$, and in the 6-12-month-old group, the two most common viruses were also RSV (11.89\%, 98/ 824) and PIV3 (4.25\%, 35/824). In the 1-2-year-old group, the top two respiratory viruses were RSV $(6.58 \%$, $48 / 730)$ and IFA $(5.75 \%, 42 / 730)$. In the 2-6-year-old group, the pathogen with the highest detection rate was ADV (5.80\%, 86/1482), followed by IFA (4.45\%, 66/ $1482)$. In the 6-12-year-old group, IFA $(9.84 \%, 69 / 701)$ and IFB $(5.42 \%, 38 / 701)$ were the top two detected viruses. Among the 12-18-year-old group, IFA (20.48\%, $17 / 83$ ) was the most common respiratory virus, followed by $\operatorname{ADV}(4.82 \%, 4 / 83)$ and $\operatorname{IFB}(4.82 \%, 4 / 83)$.

Two distinct trends in virus detection rates were observed in different age groups. The detection rate of RSV decreased with age and detection of influenza A and B increased with age. PIVs were more frequently detected in children younger than 6 years. Among them, PIV3 was predominantly obtained from patients under 2 years old. PIV1, PIV2 and ADV showed a peak of detection in the 1-6-year-old group. The detection rate of respiratory viruses differed significantly among the age groups $(P<0.05)$.

\section{Seasonal Distribution}

In this study, we analyzed the virus detection rates from January 2019 to December 2019. The results were divided into four seasons by combining astronomical seasons with climatic seasons in Guangdong province, China: spring (March, April and May), summer (June, July and August), autumn (September, October and November) and winter (December, January and February). As shown in Fig. 4, the virus detection rates in winter and spring (from December to May) were $35.08 \%$ (221/ $630)$ and $37.13 \%$ (398/1072), which were significantly higher than those in summer, at $16.99 \%(285 / 1677)$, and autumn, at $19.04 \%(195 / 1024)(P<0.05)$. The virus detection rate was highest in January $42.17 \%$ (167/396), followed by April 37.18\% (132/355), while the lowest virus detection rate was in June, at $10.41 \%$ (105/1009).
For RSV, three peak months were identified, in January $17.17 \%$ (68/396), March $14.14 \%$ (82/580) and February $12.50 \%(12 / 96)$. For ADV, three peak months were identified, in July $11.76 \%$ (30/255), January $8.33 \%$ (33/ $396)$ and October $7.23 \%(17 / 235)$. The detection rate of IFA peaked in December, at $21.28 \%$ (83/390), followed by January, at $8.59 \%(34 / 396)$. The detection rate of IFB was highest in April, at $15.21 \%$ (54/355). In the seasonal distribution of viruses, the highest detection rates of PIV1, PIV2 and PIV3 were in March $5.00 \%$ (29/580), November $3.76 \%(12 / 319)$ and July $7.06 \%$ (18/255), respectively. The detection rates of respiratory viruses differed significantly among different months $(P<0.05)$.

\section{Clinical Indicators and Symptoms Associated with Respiratory Viruses}

In this study, we statistically analyzed pediatric patients who had clinical data in their medical record. The mean respiratory rate of PIV1 positive pediatric patients was $36.18 \pm 13.00$ breaths $/ \mathrm{min}$, significantly faster than that of PIV1 negative pediatric patients $(P<0.05)$. The mean value of maximum body temperature of IFA positive pediatric patients was $39.46 \pm 0.55^{\circ} \mathrm{C}$, which was considerably higher than that of IFA negative pediatric patients. The shortest and longest duration of fever were shown by PIV1 positive pediatric patients $(3.46 \pm 2.81$ days) and PIV2 positive pediatric patients $(6.00 \pm 5.35$ days) (Table 1 and Additional file 2).

In this study, fever was the most common clinical symptom and was identified in $75.88 \%(2136 / 2815)$ of pediatric patients with ARI, followed by cough $73.29 \%$ (2063/2815), nasal discharge $13.39 \%$ (377/2815) and nasal congestion $11.90 \%(335 / 2815)$.

Symptoms associated with infection of IFA were fever, shivering, nasal congestion, abdominal pain and neurological symptoms $(P<0.05)$. Compared with the $12-14$ year age group, younger patients $(<12$ years) had a lower risk of being IFB positive. Infection of ADV was associated with fever, shivering and shortness of breath $(P<$ 0.05). Only cough was associated with RSV infection. Laboratory confirmation of PIV1 and PIV3 was associated with absence of fever. No clinical symptoms were associated with PIV2 infection $(P>0.05)$ (Tables 1 and 2 and Additional file 2).

\section{Clinical Diagnosis Associated with Respiratory Viruses}

The clinical diagnosis was divided into upper respiratory tract infection (URTI), lower respiratory tract infection (LRTI) and severe pneumonia. The virus detection rates in patients with URTI, LRTI, and severe pneumonia 
Table 1 Clinical Indicators and Clinical Symptoms Associated with Respiratory Viruses Positive

\begin{tabular}{llllllll}
\hline Characteristics & IFA & IFB & ADV & RSV & PIV1 & PIV2 & PIV3 \\
\hline Clinical indicators & & & & & & \\
Respiratory rate (breaths/min) & $28.33 \pm 5.77$ & $22.00 \pm 11.04$ & $30.50 \pm 12.02$ & $30.17 \pm 9.81$ & $36.18 \pm 13.00$ & $26.33 \pm 6.50$ & $24.33 \pm 8.50$ \\
Duration of fever (days) & $5.00 \pm 6.27$ & $4.23 \pm 3.72$ & $4.60 \pm 4.63$ & $4.03 \pm 2.83$ & $3.46 \pm 2.81$ & $6.00 \pm 5.35$ & $5.42 \pm 4.35$ \\
Check body temperature $\left({ }^{\circ} \mathrm{C}\right)$ & $37.88 \pm 0.94$ & $33.07 \pm 12.43$ & $32.50 \pm 14.52$ & $30.71 \pm 14.93$ & $35.56 \pm 8.67$ & $30.04 \pm 16.81$ & $23.90 \pm 18.96$ \\
Maximum body temperature $\left({ }^{\circ} \mathrm{C}\right)$ & $39.46 \pm 0.55$ & $36.54 \pm 10.53$ & $35.88 \pm 11.74$ & $33.51 \pm 13.90$ & $39.04 \pm 0.59$ & $29.77 \pm 19.85$ & $27.20 \pm 18.88$ \\
Clinical Symptoms ${ }^{\mathrm{a}}$ & & & & & & \\
Cyanosis & $0(0.00)$ & $0(0.00)$ & $1(0.82)$ & $5(1.95)$ & $1(2.00)$ & $0(0.00)$ & $0(0.00)$ \\
Fever & $112(94.10)$ & $34(85.00)$ & $110(89.40)$ & $167(70.50)$ & $23(79.30)$ & $17(89.50)$ & $60(61.20)$ \\
Shivering & $8(6.67)$ & $1(2.04)$ & $9(7.38)$ & $1(0.40)$ & $1(2.00)$ & $0(0.00)$ & $0(0.00)$ \\
Nasal congestion & $21(17.50)$ & $3(6.12)$ & $20(16.39)$ & $47(18.36)$ & $4(8.00)$ & $2(13.30)$ & $19(20.21)$ \\
Nasal discharge & $18(15.00)$ & $3(6.12)$ & $22(18.03)$ & $46(17.97)$ & $8(15.70)$ & $4(26.700)$ & $17(18.48)$ \\
Sore throat & $6(5.00)$ & $2(4.08)$ & $4(3.28)$ & $2(0.78)$ & $0(0.00)$ & $0(0.00)$ & $0(0.00)$ \\
Cough & $80(66.67)$ & $37(75.51)$ & $89(72.95)$ & $224(87.50)$ & $43(86.00)$ & $18(100.00)$ & $88(87.81)$ \\
Chest tightness & $1(0.83)$ & $0(0.00)$ & $1(0.82)$ & $8(3.13)$ & $1(2.00)$ & $1(5.00)$ & $2(2.17)$ \\
Shortness of breath & $6(5.00)$ & $2(4.08)$ & $13(10.66)$ & $23(8.98)$ & $1(2.00)$ & $0(0.00)$ & $8(870)$ \\
Nausea & $1(0.97)$ & $0(0.00)$ & $0(0.00)$ & $0(0.00)$ & $1(0.2 .00)$ & $0(0.00)$ & $0(0.00)$ \\
Abdominal pain & $6(6.19)$ & $1(2.04)$ & $0(0.00)$ & $1(0.39)$ & $0(0.00)$ & $0(0.00)$ & $0(0.00)$ \\
Neurological symptoms & $6(6.19)$ & $1(2.04)$ & $40.34)$ & $2(0.78)$ & $1(2.00)$ & $0(0.00)$ & $1(1.09)$ \\
\hline Non) &
\end{tabular}

Note: ${ }^{\text {a }}$ case (\%)

were $31.53 \%$ (257/815), $23.20 \%$ (301/1297), and $35.94 \%$ (23/64), respectively.

The detection rates of IFA and IFB in URTI were $6.01 \%(49 / 815)$ and $3.07 \%(25 / 815)$, higher than those in LRTI $(P<0.05)$. The pediatric patients who were infected with IFA and IFB were more likely to be diagnosed with URTI (Fig. 5). Pediatric patients infected with ADV were more likely to be diagnosed with severe pneumonia $9.38 \%(6 / 64)(P<0.05)$. RSV mainly caused severe pneumonia and LRTI, with detection rates of $12.50 \%(8 / 64)$ and $10.33 \%$ (134/1297), respectively. PIV3 caused a higher proportion of severe pneumonia $(6.25 \%, 4 / 64)$.

\section{Discussion}

Acute respiratory infection (ARI) is a common clinical disease and defining the cause is deceptively difficult [6]. Accurate and rapid identification of pathogens causing acute respiratory infection is essential for the application of appropriate antiviral therapy and the prevention of overuse of antibiotics. Although there are many reports of retrospective analyses of respiratory virus infection in Guangdong, China, few articles report comprehensive analyses from multiple hospitals. In this study, 4403 pediatric patients aged $0-18$ years were recruited from 16 hospitals in 10 cities of Guangdong, China in 2019, namely Guangzhou, Zhuhai, Shenzhen, Dongguan,
Huizhou, Zhanjiang, Zhongshan, Yangjiang, Jiangmen and Foshan (Additional file 1).

In our study, the detection rate of respiratory viruses in children with ARI was $24.96 \%$. In other studies, the rates ranged from 24.5 to $72.3 \%$ in other regions of China and other countries [4, 5, 7-9], which indicates the complexity and diversity of ARI etiology. RSV and IFA were the two most frequently detected viruses in this study. This result is in good agreement with some previous studies [9-11], but differs from other studies $[12,13]$. Our study indicated that RSV was the dominate cause of respiratory infection in children and the detection rate of RSV decreased with age, owing to the maturation of the immune system [14]; this finding was similar to previous reports $[9,11,15]$. IFA was the second most common respiratory virus. Influenza virus prevalence increased with age, which agreed with previous reports $[8,11]$, but differed from another study [9], and may be due to a greater opportunity for transmission within day care or preschool and more frequent social mixing by older children and those of school age [16]. In this study, the detection rate of ADV was the third highest, and it was more likely to infect preadolescents $(2-12$ years old $)(P<0.05)$; it is considered to be an important cause of respiratory tract infections in children [17]. Owing to the variability in virus transmission dynamics among humans, such as the reproductive number (R0), the rate of mutation accumulation, the duration of immunity, and the presence of cross- 
Table 2 Multivariate Logistic Regression Analysis of Clinical characteristics associated with respiratory viruses

\begin{tabular}{|c|c|c|c|c|c|c|c|c|c|c|c|c|c|}
\hline & IFA & & IFB & & ADV & & RSV & & PIV1 & & PIV2 & PIV3 & \\
\hline & $\mathrm{OR}(95 \% \mathrm{Cl})$ & $P$ & OR(95 \%Cl) & $P$ & OR(95 \%Cl) & $P$ & $\mathrm{OR}(95 \% \mathrm{Cl})$ & $P$ & $\mathrm{OR}(95 \% \mathrm{Cl})$ & $P$ & $P$ & $\mathrm{OR}(95 \% \mathrm{Cl})$ & $P$ \\
\hline Sex & & NS & & NS & & NS & & NS & & NS & NS & & NS \\
\hline \multicolumn{14}{|l|}{ Age groups } \\
\hline$(0-6) \mathrm{mo}$ & & NS & $\begin{array}{l}0.049 \\
(0.010- \\
0.235)\end{array}$ & 0.000 & & NS & & NS & & NS & NS & & NS \\
\hline$(6-12) \mathrm{mo}$ & & NS & $\begin{array}{l}0.043 \\
(0.010- \\
0.186)\end{array}$ & 0.000 & & NS & & NS & & NS & NS & & NS \\
\hline$(1-2) \mathrm{yr}$ & & NS & $\begin{array}{l}0.016 \\
(0.002- \\
0.149)\end{array}$ & 0.000 & & NS & & NS & & NS & NS & & NS \\
\hline$(2-6) \mathrm{yr}$ & & NS & $\begin{array}{l}0.176 \\
(0.056- \\
0.552)\end{array}$ & 0.003 & & NS & & NS & & NS & NS & & NS \\
\hline$(6-12) y r$ & & NS & $\begin{array}{l}0.205 \\
(0.060- \\
0.697)\end{array}$ & 0.011 & & NS & & NS & & NS & NS & & NS \\
\hline$(12-18) y r$ & & NS & $-^{a}$ & & & NS & & NS & & NS & NS & & NS \\
\hline \multicolumn{14}{|l|}{ Clinical Symptoms } \\
\hline Cyanosis & & NS & & NS & & NS & & NS & & NS & NS & & NS \\
\hline Fever & $\begin{array}{l}3.847 \\
(1.836- \\
8.061)\end{array}$ & 0.000 & & NS & $\begin{array}{l}1.635 \\
(1.006- \\
2.659)\end{array}$ & 0.047 & & NS & $\begin{array}{l}0.305 \\
(0.167- \\
0.556)\end{array}$ & 0.000 & NS & $\begin{array}{l}0.550 \\
(0.351- \\
0.863)\end{array}$ & 0.009 \\
\hline Shivering & $\begin{array}{l}2.733 \\
(1.173- \\
6.366)\end{array}$ & 0.020 & & NS & $\begin{array}{l}3.251 \\
(1.514- \\
6.981)\end{array}$ & 0.002 & & NS & & NS & NS & & NS \\
\hline $\begin{array}{l}\text { Nasal } \\
\text { congestion }\end{array}$ & $\begin{array}{l}2.314 \\
(1.200- \\
4.461)\end{array}$ & 0.012 & & NS & & NS & & NS & & NS & NS & & NS \\
\hline Nasal discharge & & NS & & NS & & NS & & NS & & NS & NS & & NS \\
\hline Sore throat & & NS & & NS & & NS & & NS & & NS & NS & & NS \\
\hline Cough & & NS & & NS & & NS & $\begin{array}{l}2.152 \\
(1.399- \\
3.308)\end{array}$ & 0.000 & & NS & NS & & NS \\
\hline Chest tightness & & NS & & NS & & NS & & NS & & NS & NS & & NS \\
\hline $\begin{array}{l}\text { Shortness of } \\
\text { breath }\end{array}$ & & NS & & NS & $\begin{array}{l}2.838 \\
(1.497-5.38)\end{array}$ & 0.001 & & NS & & NS & NS & & NS \\
\hline Nausea & & NS & & NS & & NS & & NS & & NS & NS & & NS \\
\hline $\begin{array}{l}\text { Abdominal } \\
\text { pain }\end{array}$ & $\begin{array}{l}2.809 \\
(1.126- \\
7.011)\end{array}$ & 0.027 & & NS & & NS & & NS & & NS & NS & & NS \\
\hline $\begin{array}{l}\text { Neurological } \\
\text { symptoms }\end{array}$ & $\begin{array}{l}3.642 \\
(1.450- \\
9.145)\end{array}$ & 0.006 & & NS & & NS & & NS & & NS & NS & & NS \\
\hline
\end{tabular}

Note: For each virus, an independent multivariate regression analysis was performed (i.e. whatever the virological result, positive or negative)

a: Reference group; NS no significant.

protection [8], the age distribution of these viruses shows diversity which may contribute to the determination of appropriate pediatric care and disease diagnosis.

ARI is frequently seasonal, particularly in regions with temperate climates [18]. In the Northern Hemisphere, respiratory viruses are reported to be more active from
November to March [19]. In our study, the same trend was shown: the virus detection rate in winter (December, January, February) and spring (March, April, May) was higher than that in summer and autumn. However, in February, the detection rate of the virus was significantly lower than that of the other 2 months (December and 


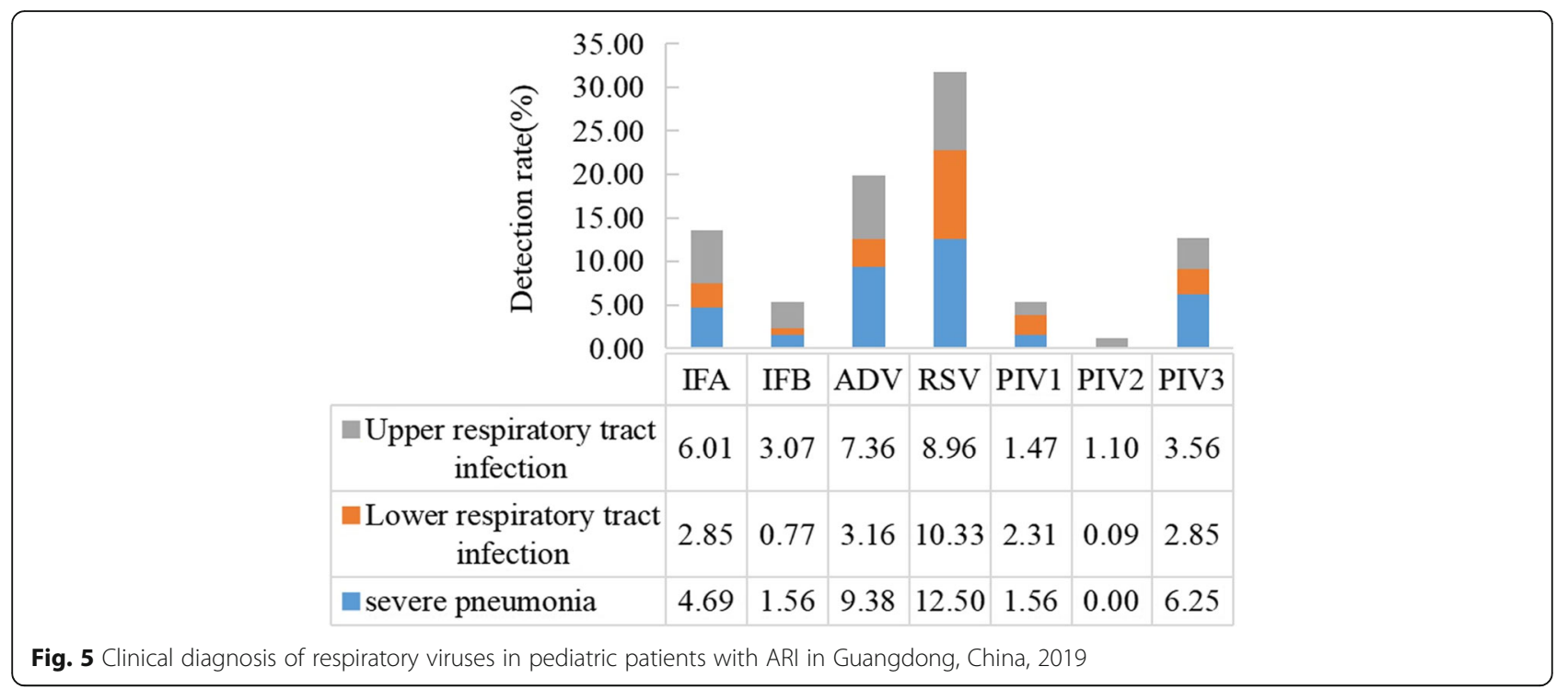

January). A possible reason might be that the Chinese Lunar New Year occurs in February, and many people go home for the Spring Festival holiday. In addition, Guangdong Province is a large province with a floating population, and in February the population aggregation in public places decreases significantly. Infection with IFA, IFB and RSV was seasonal, with high incidence in winter and spring, consistent with findings reported in Spain, the USA [20, 21], and Shanghai, China [4], but different from Qingdao, China [18], and other counties $[9,22,23]$, which suggested that there were regional differences in virus prevalence. The detection rate of ADV peaked in July 2019 (10.51\%), which was similar to what has been found in Beijing, China [24], where ADV was primarily detected in the summer; however, in Kuwait, peaks occurred in November and March [25]. In our study, many cases of PIV2 infection were detected in the autumn-winter season, while PIV3 showed clear seasonality with yearly outbreaks in the spring-summer season, consistent with a previous report [26], but PIV1 infections peaked in spring, not in autumn. Seasonal variation may correlate with viral interference [27]; China's complex climate, including low temperature, humidity, and precipitation, and geography, as well as its diverse socioeconomic and demographic characteristics, have led to different patterns of seasonal virus infections, suggesting that more studies are needed to guide vaccination times in the south of China [28].

In our study, it was shown that the most common clinical symptoms were fever and cough in children with acute respiratory infection, consistent with a previous report [29]. Our data suggested that cough was associated with RSV detection. RSV infection was more likely to be associated with lower respiratory tract infection $(10.33 \%)$ and severe pneumonia (12.5\%), as previously reported $[13,30]$, which indicated that it was necessary to pay more attention to RSV infection. Symptoms associated with infection of IFA were fever, shivering, nasal congestion, abdominal pain and neurological symptoms. More influenza cases had high fever at hospital admission than those without influenza [31]. This suggested that, in the influenza epidemic season, children with high fever should be first assessed for IFA infection, and need active treatment to reduce the possibility of febrile seizures. PIV1 and PIV3 were associated with absence of fever, which indicated that if there was no fever a patient may be infected with PIV1 or PIV3. However, the symptoms of respiratory virus infections are usually clinically similar, so it is very important that the detection of pathogen infection through direct or indirect fluorescence and other laboratory tests be used to provide clinicians with diagnostic evidence.

This study reflected the respiratory virus infections in pediatric patients with ARI in Guangdong, China during 2019. The large data set from 16 hospitals provided an adequate database, which allowed us to draw meaningful conclusions regarding the agents.

Regrettably, some other common respiratory viruses and bacteria were not included in our study and the pathogens detected by direct immunofluorescence antibody assay are extremely limited. Further studies should be undertaken and continuous surveillance periods should provide more information concerning the epidemiology of respiratory virus infections, the pathogenesis and interactions of co-infections and their associations with clinical outcomes.

\section{Conclusions}

We found that respiratory viruses were statistically associated with age and season. Appropriate knowledge and 
understanding of the clinical symptoms of these respiratory illnesses may contribute to developing better strategies for therapy and prevention.

\section{Abbreviations}

ADV: Adenoviruses; ARI: Acute respiratory infections; IFA: Influenza A virus; IFB: Influenza B virus; LRTI: Lower respiratory tract infection; PIV: Parainfluenza virus; RSV: Respiratory syncytial virus; URTI: Upper respiratory tract infection

\section{Supplementary Information}

The online version contains supplementary material available at https://doi. org/10.1186/s12887-021-02759-0.

Additional file 1: Geographic regions of respiratory viruses study covered (10 cities, in color area).

Additional file 2: Clinical Indicators and Clinical Symptoms Associated with Respiratory Viruses Negative.

Additional file 2: Clinical Indicators and Clinical Symptoms Associated with Respiratory Viruses Negative.

\section{Acknowledgements}

We thank the directors and staff members of the participating hospitals and the physicians and nurses who contributed to the study: Hongfeng Liang, Chunjie Liang, Guanjun Huang, Youming Liao, Qikang Wu, and Jinhui Liu. We also thank Yadong Yang and Yulin Lai who provided technical support.

\section{Authors' contributions}

$X H$ and $L Z$ designed the study. JY, NY, XM, BH, WL, FQ, FZ, CC, YZ, BZ, TC, WW, XW, YZ, BS, SL, NL, XL, ZL, XL, CW, CY, PF, HW, SZ, YX, ML and WJ participated in data collection and analysis. GW performed the statistical analysis. YZ and LQ drafted the manuscript. All authors have critically read and commented on draft versions of the report, and approved the final version.

\section{Funding}

This study was supported by funds from the Guangdong Medical Association NO.303(2018), the National Natural Science Foundation of China (81672076,81601819), and the Outstanding Youths Development Scheme of Nanfang Hospital, Southern Medical University (2016J013).

\section{Availability of data and materials}

The data and materials supporting the conclusions of the study are available from the corresponding author on reasonable request.

\section{Declarations}

\section{Ethics approval and consent to participate}

This was a retrospective, observational study. This study was approved by the Institutional Research Ethics Committee of Southern Medical University (NFEC-2020-023). Written informed consent was obtained from the parents or guardians of the participants before clinical data. The data analyzed in our study were anonymized before its use.

\section{Consent for publication}

Not applicable.

\section{Competing interests}

The authors declare that they have no competing interests.

\section{Author details}

'Department of Laboratory Medicine, Nanfang Hospital, Southern Medical University, Guangzhou, China. ${ }^{2}$ Guangdong 999 Brain Hospital, Guangzhou, China. ${ }^{3}$ Yangjiang People's Hospital, Yangjiang, China. ${ }^{4}$ Zhujiang Hospital, Southern Medical University, Guangzhou, China. ${ }^{5}$ Guangdong Women and

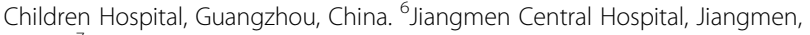
China. ${ }^{7}$ The Third Affiliated Hospital of Sun Yat-sen University, Guangzhou, China. ${ }^{8}$ The First People's Hospital of Foshan, Foshan, China. ${ }^{9}$ Nanhai Hospital, Southern Medical University, Foshan, China. ${ }^{10}$ The Fifth Affiliated
Hospital of Southern Medical University, Guangzhou, China. ${ }^{11}$ Central People's Hospital of Zhanjiang, Zhanjiang, China. ${ }^{12}$ Zhuhai Maternal and Child Health Hospital, Zhuhai, China. ${ }^{13}$ Dongguan People's Hospital, Dongguan, China. ${ }^{14}$ Nanhai District People's Hospital of Foshan, Foshan, China. ${ }^{15}$ Zhongshan People's Hospital, Zhongshan, China. ${ }^{16}$ Central People's Hospital of Huizhou, Huizhou, China. ${ }^{17}$ Shenzhen Hospital of Southern Medical University, Shenzhen, China. ${ }^{18}$ School of Economics, Jinan University, Guangdong, Guangzhou, China. ${ }^{19}$ Nanfang College of Sun Yat-Sen University, Guangdong, Guangzhou, China. ${ }^{20}$ The Seventh Affiliated Hospital, Sun Yat-Sen University, Guangdong, Guangdong, China.

Received: 3 March 2021 Accepted: 3 June 2021

Published online: 17 June 2021

\section{References}

1. He C, Liu L, Chu Y, Perin J, Dai L, Li X, Miao L, Kang L, Li Q, Scherpbier R et al: National and subnational all-cause and cause-specific child mortality in China, 1996-2015: a systematic analysis with implications for the Sustainable Development Goals. The Lancet Global Health. 2017; 5(2):e186e97.

2. Echavarria M, Marcone DN, Querci M, Seoane A, Ypas M, Videla C, O'Farrell C, Vidaurreta S, Ekstrom J, Carballal G: Clinical impact of rapid molecular detection of respiratory pathogens in patients with acute respiratory infection. J Clin Virol. 2018; 108:90-5.

3. Lee BR, Hassan F, Jackson MA, Selvarangan R: Impact of multiplex molecular assay turn-around-time on antibiotic utilization and clinical management of hospitalized children with acute respiratory tract infections. J Clin Virol. 2019; 110:11-6.

4. Liu P, Xu M, He L, Su L, Wang A, Fu P, Lu L, Wang C, Xu J: Epidemiology of Respiratory Pathogens in Children with Lower Respiratory Tract Infections in Shanghai, China, from 2013 to 2015. Jpn J Infect Dis. 2018; 71(1):39-44.

5. Liu J, Wang M, Zhao Z, Lin X, Zhang P, Yue Q, Zhang T, Meng Y: Viral and bacterial coinfection among hospitalized children with respiratory tract infections. Am J Infect Control. 2020;48(10):1231-36.

6. Zaas AK, Garner BH, Tsalik EL, Burke T, Woods CW, Ginsburg GS: The current epidemiology and clinical decisions surrounding acute respiratory infections. Trends Mol Med. 2014; 20(10):579-88.

7. He Y, Lin GY, Wang Q, Cai XY, Zhang YH, Lin CX, Lu CD, Lu XD: A 3-year prospective study of the epidemiology of acute respiratory viral infections in hospitalized children in Shenzhen, China. Influenza Other Respir Viruses. 2014; 8(4):443-51.

8. Caini S, de Mora D, Olmedo M, Portugal D, Becerra MA, Mejia M, Pacurucu MC, Ojeda J, Bonaccorsi G, Lorini C et al: The epidemiology and severity of respiratory viral infections in a tropical country: Ecuador, 2009-2016. J Infect Public Health. 2019; 12(3):357-63.

9. Kurskaya O, Ryabichenko T, Leonova N, Shi W, Bi H, Sharshov K, Kazachkova E, Sobolev I, Prokopyeva E, Kartseva T et al: Viral etiology of acute respiratory infections in hospitalized children in Novosibirsk City, Russia (2013-2017). PLoS One. 2018; 13(9): e0200117.

10. Liu WK, Chen DH, Tan WP, Qiu SY, Xu D, Zhang L, Gu SJ, Zhou R, Liu Q: Paramyxoviruses respiratory syncytial virus, parainfluenza virus, and human metapneumovirus infection in pediatric hospitalized patients and climate correlation in a subtropical region of southern China: a 7-year survey. Eur J Clin Microbiol Infect Dis. 2019; 38(12):2355-64.

11. Grunberg M, Sno R, Adhin MR: Epidemiology of respiratory viruses in patients with severe acute respiratory infections and influenza-like illness in Suriname. Influenza Other Respir Viruses. 2021; 15(1):72-80.

12. Hassan DA, Rachid SK, Ziebuhr J: A Single-Center Study of Viral Respiratory Tract Infections in Hospitalized Children From the Kurdistan Region of Iraq. Glob Pediatr Health. 2018; 5:2333794 × 18784996.

13. Furuse $Y$, Tamaki R, Suzuki A, Kamigaki T, Okamoto M, Saito-Obata M, Nakagawa E, Saito M, Segubre-Mercado E, Tallo V et al: Epidemiological and clinical characteristics of children with acute respiratory viral infections in the Philippines: a prospective cohort study. Clinical Microbiology and Infection. 2020 Sep 17: S1198-743 × (20)30569-3.

14. Shi T, McAllister DA, O'Brien KL, Simoes EAF, Madhi SA, Gessner BD, Polack FP, Balsells E, Acacio S, Aguayo C et al: Global, regional, and national disease burden estimates of acute lower respiratory infections due to respiratory syncytial virus in young children in 2015: a systematic review and modelling study. The Lancet. 2017; 390(10098):946-58. 
15. Fine J, Bray-Aschenbrenner A, Williams H, Buchanan P, Werner J: The Resource Burden of Infections With Rhinovirus/Enterovirus, Influenza, and Respiratory Syncytial Virus in Children. Clin Pediatr (Phila). 2019; 58(2):17784.

16. Fowlkes A, Dasgupta S, Chao E, Lemmings J, Goodin K, Harris M, Martin K, Feist M, Wu W, Boulton R et al: Estimating influenza incidence and rates of influenza-like illness in the outpatient setting. Influenza Other Respir Viruses. 2013; 7(5):694-700.

17. Liu C, Xiao Y, Zhang J, Ren L, Li J, Xie Z, Xu B, Yang Y, Qian S, Wang J et al: Adenovirus infection in children with acute lower respiratory tract infections in Beijing, China, 2007 to 2012. BMC Infect Dis. 2015; 15:408.

18. Liu GS, Li H, Zhao SC, Lu RJ, Niu PH, Tan WJ: Viral and Bacterial Etiology of Acute Febrile Respiratory Syndrome among Patients in Qinghai, China. Biomed Environ Sci. 2019; 32(6):438-45.

19. Cicek C, Arslan A, Karakus HS, Yalaz M, Saz EU, Pullukcu H, Cok G: [Prevalence and seasonal distribution of respiratory viruses in patients with acute respiratory tract infections, 2002-2014]. Mikrobiyol Bul. 2015; 49(2): 188-200.

20. Choe YJ, Park S, Michelow IC: Co-seasonality and co-detection of respiratory viruses and bacteraemia in children: a retrospective analysis. Clin Microbiol Infect. 2020; 26:1690.e5-e8.

21. Smithgall M, Maykowski $P$, Zachariah P, Oberhardt M, Vargas CY, Reed C, LaRussa P, Saiman L, Stockwell MS: Epidemiology, clinical features, and resource utilization associated with respiratory syncytial virus in the community and hospital. Influenza Other Respir Viruses. 2020; 14(3):247-56.

22. Elhakim M, Hafiz Rasooly M, Fahim M, Sheikh Ali S, Haddad N, Cherkaoui I, Hjaija D, Nadeem S, Assiri A, Aljifri A et al: Epidemiology of severe cases of influenza and other acute respiratory infections in the Eastern Mediterranean Region, July 2016 to June 2018. J Infect Public Health. 2020; 13(3):423-9.

23. Fullana Barcelo MI, Asensio Rodriguez J, Artigues Serra F, Ferre Beltran A Salva D'agosto P, Almodovar Garcia M, Lopez Bilbao MDC, Sanchis Cortes P, Reina Prieto J, Riera Jaume M: Epidemiological and clinical characteristics of community-acquired and nosocomial influenza cases and risk factors associated with complications: A four season analysis of all adult patients admitted in a tertiary hospital. Influenza Other Respir Viruses. 2020;00:1-9.

24. Yao LH, Wang C, Wei TL, Wang H, Ma FL, Zheng LS: Human adenovirus among hospitalized children with respiratory tract infections in Beijing, China, 2017-2018. Virol J. 2019; 16(1):78.

25. Chehadeh W, Al-Adwani A, John SE, Al-Dhufairi S, Al-Dousari H, Alkhaledi M, Al-Nakib W: Adenovirus types associated with severe respiratory diseases: A retrospective 4-year study in Kuwait. J Med Virol. 2018; 90(6):1033-9.

26. Mizuta K, Abiko C, Aoki Y, Ikeda T, Itagaki T, Katsushima F, Katsushima Y, Matsuzaki $Y$, Noda $M$, Kimura $\mathrm{H}$ et al: Epidemiology of parainfluenza virus types 1, 2 and 3 infections based on virus isolation between 2002 and 2011 in Yamagata, Japan. Microbiol Immunol. 2012; 56(12):855-8.

27. van Asten L, Bijkerk P, Fanoy E, van Ginkel A, Suijkerbuijk A, van der Hoek W, Meijer A, Vennema H: Early occurrence of influenza A epidemics coincided with changes in occurrence of other respiratory virus infections. Influenza Other Respir Viruses. 2016; 10(1):14-26.

28. Peng Z, Feng L, Carolyn GM, Wang K, Zhu G, Zhang Y, Hu J, Huang Y, Pan $\mathrm{H}, \mathrm{Guo} \mathrm{N}$ et al: Characterizing the epidemiology, virology, and clinical features of influenza in China's first severe acute respiratory infection sentinel surveillance system, February 2011-October 2013. BMC Infect Dis. 2015; 15:143.

29. Newcombe PA, Sheffield JK, Petsky HL, Marchant JM, Willis C, Chang AB: A child chronic cough-specific quality of life measure: development and validation. Thorax. 2016; 71(8):695-700.

30. Souty C, Masse S, Valette M, Behillil S, Bonmarin I, Pino C, Turbelin C, Capai $L$, Vilcu AM, Lina B et al: Baseline characteristics and clinical symptoms related to respiratory viruses identified among patients presenting with influenza-like illness in primary care. Clin Microbiol Infect. 2019; 25(9):114753.

31. Huai Y, Guan X, Liu S, Uyeki TM, Jiang H, Klena J, Huang J, Chen M, Peng Y, Yang $\mathrm{H}$ et al: Clinical characteristics and factors associated with severe acute respiratory infection and influenza among children in Jingzhou, China. Influenza Other Respir Viruses. 2017; 11(2):148-56

\section{Publisher's Note}

Springer Nature remains neutral with regard to jurisdictional claims in published maps and institutional affiliations.

\section{Ready to submit your research? Choose BMC and benefit from:}

- fast, convenient online submission

- thorough peer review by experienced researchers in your field

- rapid publication on acceptance

- support for research data, including large and complex data types

- gold Open Access which fosters wider collaboration and increased citations

- maximum visibility for your research: over $100 \mathrm{M}$ website views per year

At BMC, research is always in progress.

Learn more biomedcentral.com/submissions 